\title{
THE
}

$1-4-2018$

\section{Ontogenetic Partial Migration is Associated with Environmental Drivers and Influences Fisheries Interactions in a Marine Predator}

\author{
James S E Lea \\ Bradley M. Wetherbee \\ university of rhode island, wetherbee@uri.edu \\ Lara L. Sousa \\ Choy Aming \\ Neil Burnie
}

See next page for additional authors

Follow this and additional works at: https://digitalcommons.uri.edu/bio_facpubs

Creative Commons License

(c) (i)

This work is licensed under a Creative Commons Attribution 4.0 License.

\section{Citation/Publisher Attribution}

James S E Lea, Bradley M Wetherbee, Lara L Sousa, Choy Aming, Neil Burnie, Nicolas E Humphries, Nuno Queiroz, Guy M Harvey, David W Sims, Mahmood S Shivji, Handling editor: James Watson; Ontogenetic partial migration is associated with environmental drivers and influences fisheries interactions in a marine predator, ICES Journal of Marine Science, Volume 75, Issue 4, 1 July 2018, Pages 1383-1392,

https://doi.org/10.1093/icesjms/fsx238

This Article is brought to you for free and open access by the Biological Sciences at DigitalCommons@URI. It has been accepted for inclusion in Biological Sciences Faculty Publications by an authorized administrator of DigitalCommons@URI. For more information, please contact digitalcommons-group@uri.edu. 


\section{Authors}

James S E Lea, Bradley M. Wetherbee, Lara L. Sousa, Choy Aming, Neil Burnie, Nicholas E. Humphries, Nuno Queiroz, Guy M. Harvey, David W. Sims, and Mahmood S. Shivji 


\title{
ICES Journal of Marine Science
}

\section{Original Article}

\section{Ontogenetic partial migration is associated with environmental drivers and influences fisheries interactions in a marine predator}

\author{
James S. E. Lea ${ }^{1,2,3,4, *, \dagger}$, Bradley M. Wetherbee ${ }^{1,5, \dagger}$, Lara L. Sousa ${ }^{2,6,7}$, Choy Aming ${ }^{8}$, Neil Burnie ${ }^{8}$, \\ Nicolas E. Humphries ${ }^{2}$, Nuno Queiroz ${ }^{2,6}$, Guy M. Harvey ${ }^{1}$, David W. Sims ${ }^{2,7,9}$, and \\ Mahmood S. Shivji,*

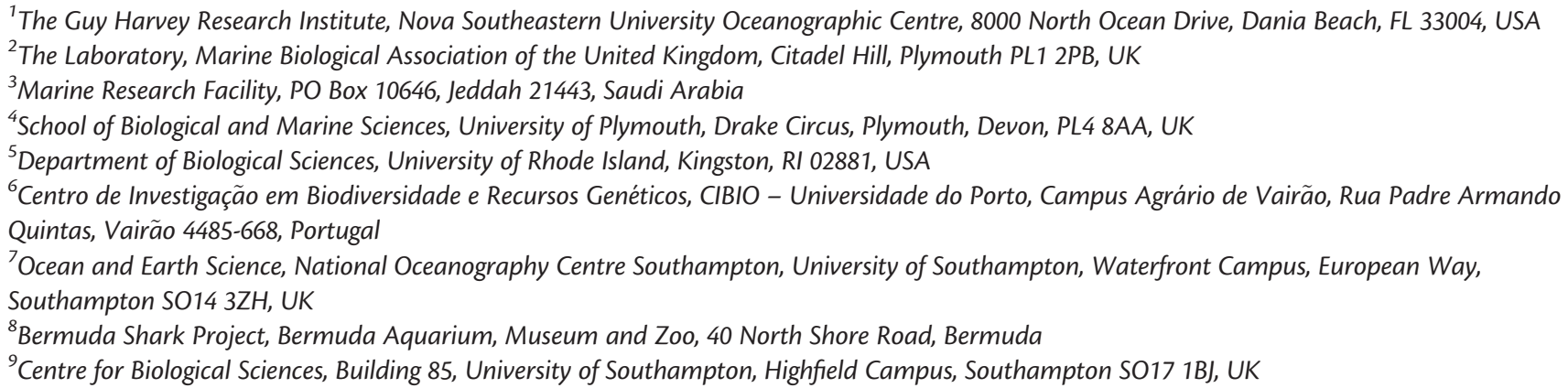

*Corresponding authors: tel: +18 005416 682; fax: +1 954-262-4098; e-mail: james@eatonlea.co.uk and mahmood@nova.edu

${ }^{\dagger}$ These authors contributed equally to this work.

Lea, J. S. E., Wetherbee, B. M., Sousa, L. L., Aming, C., Burnie, N., Humphries, N. E., Queiroz, N., Harvey, G. M., Sims, D. W., and Shivji, M. S. Ontogenetic partial migration is associated with environmental drivers and influences fisheries interactions in a marine predator. ICES Journal of Marine Science, 75: 1383-1392.

Received 14 October 2017; revised 3 December 2017; accepted 8 December 2017; advance access publication 4 January 2018.

\begin{abstract}
The ability to predict animal movement based on environmental change is essential for understanding the dynamic nature of their spatial ecology, and in turn the effectiveness of conservation strategies. We used a large marine predator that displays partial migration (the tiger shark Galeocerdo cuvier) as a model to test the role of oceanic conditions in predicting the space-use of different size classes. By using generalized additive mixed models (GAMMs), we revealed that environmental variables (sea surface temperature, primary productivity, thermal fronts, and bathymetry) had much greater predictive power for the movements of large, migratory tiger sharks than for small, resident individuals. We also found that coverage of tiger shark movements within "shark sanctuaries" (protected areas specifically for sharks) in the northwest Atlantic could be increased from 12 to $52 \%$ through inclusion of Bermuda's waters. However, as large tiger sharks are migratory, over $80 \%$ of potential longline fisheries interactions would still occur outside the boundaries of even the expanded protected areas. This emphasises that management of highly migratory species needs to be dynamic and account for changing interactions with fisheries over time, which in a changing climate may rely on predicting movements based on oceanic conditions to be effective.
\end{abstract}

Keywords: animal telemetry, conservation, environment, fisheries, foraging, Galeocerdo cuvier, migration, modelling 


\section{Introduction}

Long-distance migrations that span hemispheres or ocean basins cause significant variation in population distribution and structure, often connecting disparate ecosystems and facilitating transfer of energy between them (González-Solís et al., 2007; Block et al., 2011). Yet factors that drive, or constrain, migration, and influence the paths taken often remain elusive, particularly for marine species (Hays et al., 2016). Evaluation of such factors can help predict animal movements based on changing environmental conditions, in turn revealing how they interact with both their ecological communities and human activities, such as fishing (Hazen et al., 2013; Queiroz et al., 2016). However, movement predictions are made more difficult when migrations are partial in nature, as individuals faced with the same conditions in the same location may or may not migrate (Chapman et al., 2012). Partial migration, although increasingly recognized in fish, remains poorly understood in terms of its evolutionary and ecological drivers (Chapman et al., 2011). Partial migration also complicates sustainable management of exploited species, as areafocused fishing may result in selective depletion of certain population subunits (e.g. juveniles, mature females) that could perpetuate population declines even if other units are relatively free from exploitation (Wearmouth and Sims, 2008). Consequently, the ability to predict animal movements based on environmental variation (e.g. temperature gradients, prey availability), including characteristics of partial migration, is valuable both for understanding their basic ecology and helping management initiatives aimed at promoting population sustainability.

Characterizing the long-term migration patterns and their drivers for large-bodied sharks remains challenging (Weng et al., 2008; Domeier and Nasby-Lucas, 2013; Papastamatiou et al., 2013), hampering understanding of their basic ecology as well as effective conservation planning. Of concern is that certain studies indicate that shark populations in some regions may have been reduced to $<10 \%$ of pre-exploitation levels (Baum and Myers, 2004; Ferretti et al., 2008; Dulvy et al., 2014) as 63-273 million sharks are caught annually in fisheries worldwide (Worm et al., 2013). One large-bodied species, the tiger shark Galeocerdo cuvier, provides a tractable model for investigating the long-term movement ecology of highly migratory marine predators. Tiger sharks are capable of dispersing thousands of kilometres (Hammerschlag et al., 2012; Papastamatiou et al., 2013; Werry et al., 2014; Afonso et al., 2017), including repeated, philopatric migrations between the disparate ecosystems of insular Caribbean reefs and open ocean areas of the Atlantic over $2500 \mathrm{~km}$ away (Lea et al., 2015). Partial migration was also evident: only individuals above a certain body size $(>270 \mathrm{~cm}$ total length) performed the longdistance migrations, with immature smaller individuals remaining resident near the tagging site of Bermuda (Lea et al., 2015).

In the Atlantic, available catch data suggest that tiger shark populations appear to be stable (Baum and Blanchard, 2010; Carlson et al., 2012). However, tiger sharks are regularly caught in offshore longline fisheries across the Atlantic (Baum and Blanchard, 2010; Domingo et al., 2016; Dapp et al., 2017) and may be at risk of increased exploitation from fisheries switching to non-target species as preferred catches decline (Pauly et al., 1998). Combined with their Near Threatened status on the IUCN Red List (Simpfendorfer, 2009), this suggests tiger sharks in the Atlantic may benefit from precautionary management, and consideration of their migratory behaviour has important implications for their interaction with fisheries. It is necessary to identify not only where individuals are and when, but also the underlying factors that may drive their movements.

The long-distance and partial migration patterns exhibited by tiger sharks are likely a product of a combination of intrinsic factors (e.g. size, sex, physiological constraints related to energetic budgets, and thermal tolerances) and extrinsic factors such as oceanic conditions (e.g. temperature, resource distribution) (Chapman et al., 2012; Papastamatiou et al., 2013). For example, the size of an animal influences dispersal ability, and stage of maturity can have dramatic effects on migratory patterns (Chapman et al., 2012; Papastamatiou et al., 2013). Suitability of habitat is also an important driver of space use by animals, with both ambient temperature and complexity of topographic features greatly influencing movements of marine species (Block et al., 2011; Papastamatiou et al., 2015; Queiroz et al., 2016; Sousa et al., 2016). For instance, moving to stay within a certain temperature range may help ectothermic animals thermoregulate and better manage energetic budgets (McMahon and Hays, 2006), and orientation towards shallow topographic features, such as insular reefs and seamounts, is likely beneficial for access to productive waters with associated high prey density (Oschlies and Garçon, 1998). Variation in resource distribution can also significantly alter the movements of migrating animals: predators have been shown to associate with areas of higher chlorophyll- $a$ concentration, with associated high primary productivity and potential for foraging success (Block et al., 2011; Papastamatiou et al., 2013; Mansfield et al., 2014). Areas of steep thermal gradients, or fronts, have also been shown to support high abundance and diversity of predators, suggesting they are important environmental features that may aggregate prey and provide elevated foraging opportunities (Scales et al., 2014; Queiroz et al., 2016).

Consequently, the goal of our study was to expand on the identification of partial migrations in (Lea et al., 2015) by investigating intrinsic and extrinsic drivers of movement patterns in migratory marine predators, specifically testing the hypothesis of contrasting interactions with environment between size classes as a possible explanation for partial migration of tiger sharks in the northwest Atlantic. We used generalized additive mixed models (GAMMs) to determine how variation in intrinsic and extrinsic factors correlated with patterns of shark distribution, occupancy and turning frequency (as a proxy for foraging activity). Furthermore, we used spatial analysis to assess the potential risk of interaction between the tracked sharks and longline fisheries, and quantified the effectiveness of existing "shark sanctuaries" [marine protected areas (MPAs) that specifically prohibit shark fishing] for reducing these interactions.

\section{Material and methods}

Between August 2009 and July 2012, we tagged tiger sharks $(n=24)$ with Argos satellite platform terminal transmitters (SPOT5, Wildlife Computers, Redmond, Washington, USA) at

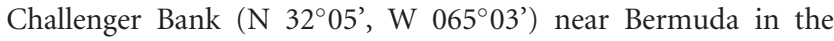
northwest Atlantic (Supplementary Table S1). All field work was approved by, and conducted with the knowledge of, the Marine Resources Section of the Bermuda Department of Environmental Protection. The shark handling and tagging methods were performed in accordance with the approved guidelines of Nova Southeastern University. 


\section{Track processing}

As Argos positions vary in frequency and quality it was necessary to process the location data to obtain normalized positions that were comparable between individuals and over time [see the Supplementary Material and Lea et al., (2015) for details]. In order for space-use analyses to be as conservative as possible, all were conducted at a grid resolution of $0.25^{\circ} \times 0.25^{\circ}$, greater than the reported errors of the worst location class [LCB, $\sim 10 \mathrm{~km}$ (Hays et al., 2001; Hazel, 2009)] and matching the lowest resolution of the environmental variables used. The combination of the coarse spatial resolution of analyses $\left(0.25^{\circ} \times 0.25^{\circ}\right)$ and high surfacing frequency of tracked sharks ( $80 \%$ of positions $<12 \mathrm{~h}$ apart) minimises any potential bias caused by SPOT tracks only providing locations when the sharks were at the surface. The total time spent within each cell (occupancy) was calculated by summing the number of 12-hourly points located within cells for each shark. The overall geographical range of tracked sharks was calculated in ArcGIS using the 95\% isopleth of the kernel density estimate for all locations, with location density normalized by calculating the mean days per grid cell (total number of positions divided by the number of tags active in that cell). To determine track sections with higher turning frequency from those with more directed movement, the turning frequency of individual trajectories was calculated for successive 12-day portions of each track, where:

$$
\begin{array}{r}
\text { Turning frequency }=1-(\text { displacement over } \\
12 \text { days/distance travelled over } 12 \text { days })
\end{array}
$$

Turning frequency was calculated over 12-day periods as this was the mean time taken for the sharks to traverse a distance greater than the error of the worst location class (LCB). Values closer to 1 indicate periods of higher turning frequency, providing a proxy for station-keeping or area-restricted searching (foraging) behaviour.

\section{Environmental data}

The environmental variables used in the different models are known to influence marine migratory animal space use (Block et al., 2011). These were: sea surface temperature (SST; a correlate of ambient water temperature), SST-slope (an approximation of thermal fronts), chlorophyll- $a$ concentration (a proxy for primary productivity), and bathymetry (an indicator of topographic features such as reefs and seamounts). SST data $\left({ }^{\circ} \mathrm{C}\right)$ were obtained from the Operational Sea Surface Temperature and Sea Ice Analysis (OSTIA) system via the U.K. National Centre for Ocean Forecasting ( $25 \mathrm{~km}$ resolution), and bathymetry data $(\mathrm{m})$ were obtained from the 2-minute Gridded Global Relief Data (ETOPO2v2). SST slope $\left({ }^{\circ} \mathrm{C}\right)$ was calculated as the maximum difference from the surrounding SST grid cells when compared to the central occupied cell. Chlorophyll- $a$ concentration $\left(\mathrm{mg} \mathrm{m}^{-3}\right)$ was obtained from Moderate Resolution Imaging Spectrometer (MODIS), GlobColour level-3 Product $0.25^{\circ}$ weekly. Each shark occupancy and turning value along a track was assigned a corresponding bathymetry, SST, SST slope, and chlorophyll- $a$ value that matched the time and location.

\section{Generalized additive mixed models}

Three generalized additive mixed models (GAMMs) were constructed to test our general hypothesis of deviance in environmental variables predicting tiger shark (i) presence/ absence across the study area, along with their (ii) occupancy, and (iii) turning frequency (see the Supplementary Material for details). Each GAMM produced separate environmental variable smooth functions for small $(n=6$, mean total length $231 \mathrm{~cm} \pm$ $33 S D)$ and large $(n=18$, mean total length $336 \mathrm{~cm} \pm 32 S D)$ sharks, with the two groups split by individuals smaller and larger than $270 \mathrm{~cm}$ total length [the partial migration cut-off identified in Lea et al., (2015)].

In order to avoid pseudo-replication and reduce potential autocorrelation between locations, as well as account for the different scales at which the environmental variables were remotely sensed, only positions separated by at least $0.25^{\circ}$ along a track were used to run each model (Queiroz et al., 2016; Sousa et al., 2016). The predictor variables were subsequently tested for collinearity using a Spearman's rank correlation matrix (Zuur et al., 2009): none of the variables exceeded the 0.75 correlation coefficient, allowing each to be included in the models. The performance of each final model output was assessed using the c index, which is equivalent to the ROC with values closer to 1 indicating better performance, and the corresponding Somers' Dxy rank correlation, which is a measure of ordinal association between the response and predictor variables. To account for variation in movement specific to the individual, shark identification code (shark ID) was incorporated into the model as a random effect. The smoothed response of each model was plotted against each environmental variable and by size of shark (small versus large) to allow comparison of behavioural response to the variables by size. In the plots, positive residual values where the confidence intervals also exceed 0 indicate where the environmental variables significantly increased the response.

\section{Estimating fisheries interactions and used of shark sanctuaries}

To map the potential risk of interaction between tiger sharks and tuna longline fisheries during the study period, reported fishing effort (number of hooks set per $5^{\circ} \times 5^{\circ}$ grid cell) during 20092012 was obtained from The International Commission for the Conservation of Atlantic Tunas (ICCAT) website (https://www. iccat.int/en/) and was multiplied by the corresponding tiger shark occupancy value for that cell (pooled and recalculated to match the $5^{\circ} \times 5^{\circ}$ of the fishing effort). This provides an estimate of where high tiger shark occupancy overlapped with high fishing effort more frequently, with the scale normalized from $0-1$ to represent the relative interaction strength.

We also evaluated the potential efficacy of existing "shark sanctuaries" [marine protected areas (MPAs) specifically for sharks] in the northwest Atlantic, as well as the effect of including the exclusive economic zone (EEZ) of Bermuda as a protected area for sharks, based on the high tiger shark occupancy of this region (Lea et al., 2015). The first existing sanctuary model includes all shark sanctuaries announced at the time of analysis: the EEZs of Bahamas, British Virgin Islands (BVI), and Saba. The second model includes the addition of Bermuda's EEZ as a potential shark sanctuary. The smaller sanctuary model encompasses an area of approximately $750000 \mathrm{~km}^{2}$, while the larger model that includes Bermuda covers approximately $1200000 \mathrm{~km}^{2}$.

The potential efficacy of both sanctuary models was determined using a grid occupancy analysis: using the boundaries of countries' EEZs, the number of days inside/outside each EEZ was 


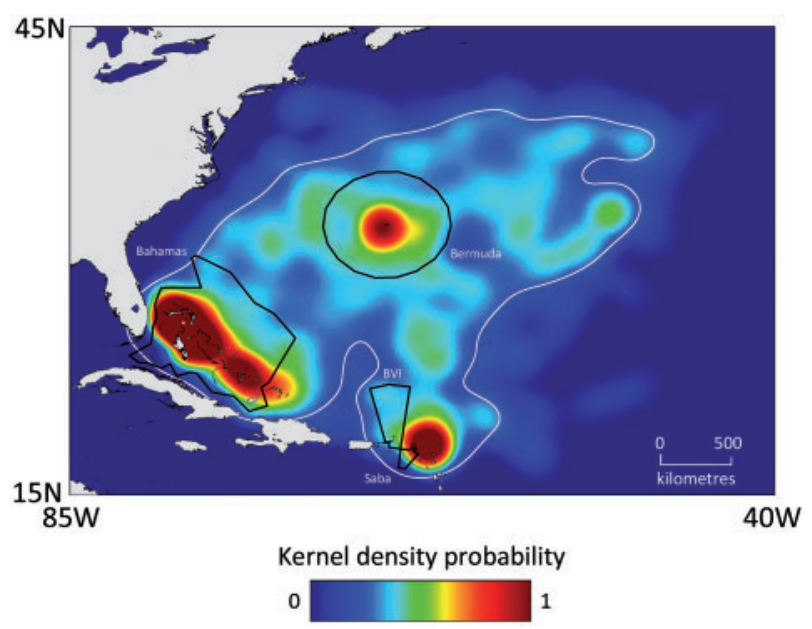

Figure 1. Kernel density plot showing broad distribution of all tracked tiger sharks, with values closer to one indicating areas of prolonged residency. The black borders denote the EEZs of the Bahamas, British Virgin Islands, Saba, and Bermuda. The white border denotes the $95 \%$ isopleth of the kernel density plot for all sharks. Map created in ArcGIS, using GSHHG coastline data.

used to calculate the proportion of each individual's recorded track that was inside each sanctuary option. Monthly proportion of time inside each sanctuary option was plotted, to see how occupancy of the EEZs changed over time. The proportion of potential longline interactions recorded within each EEZ was also calculated.

\section{Results}

Overall, tiger shark movements were tracked for a total of 411 months (mean 17.1 months \pm 9.7 SD), between August 2009 and July 2012, with individual tracking periods ranging from 41 to 1101 days (Supplementary Table S1). Individual shark size ranged from 173 to $396 \mathrm{~cm}$ total length (mean $310 \mathrm{~cm} \pm 56 S D$ ) at the time of tagging. Tiger sharks displayed extensive space-use throughout the northwest Atlantic covering 6.7 million $\mathrm{km}^{2}$, as determined by the $95 \%$ isopleth of a kernel density plot for all sharks together (Figure 1). Despite broad use of the northwest Atlantic, there were areas of prolonged residency near Bermuda, the Bahamas and other Caribbean islands such as Anguilla (Figure 1).

Given observations of partial migrations appearing to be associated with shark size, and the seasonal trends in large-scale migrations of adult sharks (Lea et al., 2015), we examined movements of the small and large sized sharks in relation to water temperatures by overlaying the latitude of all tiger shark locations on monthly averages of SST at a resolution of $0.25^{\circ}$ for the duration of the study (Figure 2). Visual inspection highlights the contrasting interaction with SST between small and large tiger shark groups: smaller individuals remaining near Bermuda $\left(\sim 32^{\circ} \mathrm{N}\right)$ experienced a range of surface temperatures across the seasons $\left(20.6{ }^{\circ} \mathrm{C} \pm 1.1 S D\right.$ in winter versus $26.4^{\circ} \mathrm{C} \pm 1.6 S D$ in summer $)$, whereas larger, migratory individuals primarily tracked along surface temperatures ranging $24-26^{\circ} \mathrm{C}\left(24.8^{\circ} \mathrm{C} \pm 1.5 S D\right.$ in winter versus $26.3^{\circ} \mathrm{C} \pm 1.9 \mathrm{SD}$ in summer), with very few locations out of this range.

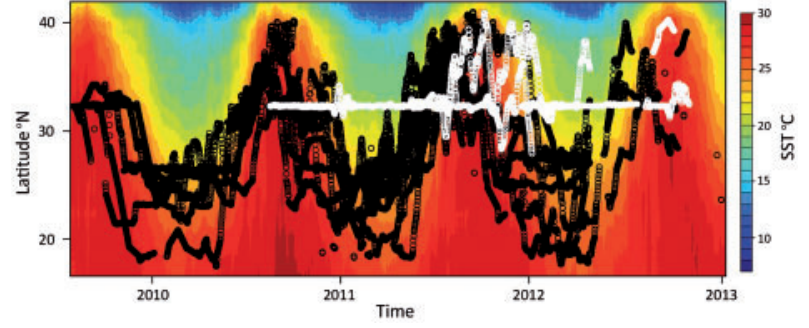

Figure 2. Latitude of tiger shark locations overlaid on monthly averages of SST at a resolution of $0.25^{\circ}$. White circles $=$ small sharks $<270 \mathrm{~cm}$ total length at tagging, black circles $=$ large sharks $>270 \mathrm{~cm}$ total length at tagging.

\section{Presence/absence GAMM}

The presence/absence GAMM predicted shark presence with moderate success, with $9 \%$ of observed variation in presence/ absence explained overall (Table 1). For smaller sharks, most of the variation was attributable to bathymetry, followed by chlorophyll-a concentration and SST slope, and the least by SST, as indicated by the F-values in the model output (Table 2). Probability of presence was typically increased in shallower habitats $(<2000 \mathrm{~m})$ of low chlorophyll- $a$ concentration, with smaller SST slopes also favoured, as indicated by where the standardized residuals and their confidence intervals exceed 0 in the plotted response curves (Figure 3).

In contrast, for the larger sharks, observable variation in presence was largely attributable to variation in SST, followed by bathymetry, chlorophyll- $a$ concentration, and SST slope, with all factors proving significant predictors (Table 2 and Figure 3). Overall, the probability of larger sharks being present increased with higher SST $\left(>21{ }^{\circ} \mathrm{C}\right)$, both high and low chlorophyll- $a$ concentration (bimodal peak), shallower waters $(<2000 \mathrm{~m})$ and steeper SST slopes $\left(>1.5^{\circ} \mathrm{C}\right.$; Table 2 and Figure 3$)$. The random effect of shark ID also had a significant effect on presence/absence (Table 2), revealing intraspecific variation in space use. The random effect of shark ID was significant for the presence/absence GAMM (Table 2), demonstrating intraspecific variation in spatial distribution.

\section{Occupancy GAMM}

In contrast to the presence/absence GAMM, the occupancy GAMM achieved much higher predictive power, with $76 \%$ of the variance being explained (Table 1). Overall, for smaller sharks, more time was spent in shallow waters, but there was a bimodal response for SST, whereby occupancy increased at temperatures below $21^{\circ} \mathrm{C}$ and above $29^{\circ} \mathrm{C}$ (Table 2 and Figure 3). This varied relationship with SST is also apparent from the tracks overlaid on SST (Figure 2). Smaller sharks also spent more time in areas with shallower thermal gradients and in regions with chlorophyll- $a$ concentrations $>0$ (Table 2 and Figure 3).

Large shark occupancy was considerably higher in shallower waters, and increased with higher chlorophyll- $a$ concentration, particularly exceeding $\sim 3 \mathrm{mg} \mathrm{m}^{-3}$ (Figure 3 ). Typically, large sharks spent more time in waters $23-27^{\circ} \mathrm{C}$ and with relatively shallow SST slopes (Figure 3), consistent with the SST-overlaid tracks (Figure 2). The random effect of shark ID was highly significant for the occupancy GAMM (Table 2), demonstrating strong intraspecific variation in where individuals spent more time. 
GAMM: presence/absence

occupancy

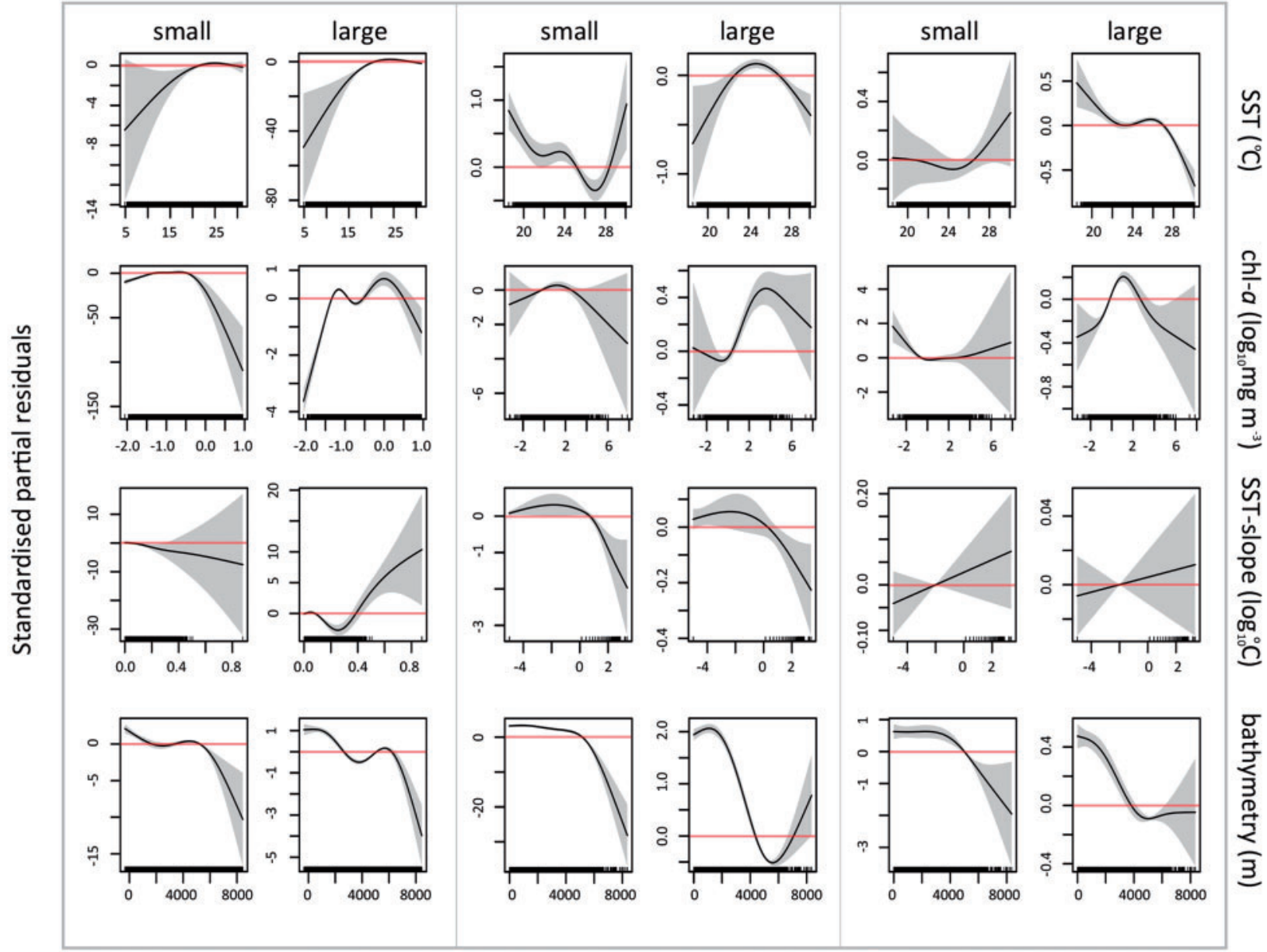

Figure 3. Overall influence of predictor variables on presence/absence for small and large tiger sharks. Note the different scales on the $y$-axes, which denote the smoothed residual values. Black tick marks above $x$-axis represent the distribution of empirical data. $Y=0$, above which the predictor positively affects the response, is marked with a line.

Table 1. Overall GAMM validation results for tiger shark presence/ absence, occupancy and turning frequency.

\begin{tabular}{llllrc}
\hline Model & C index & Dxy & SD & \multicolumn{1}{c}{ 年 } & $\begin{array}{l}\text { Variance } \\
\text { explained (\%) }\end{array}$ \\
\hline Presence/absence & 0.74 & 0.48 & 0.01 & 229808 & 8.6 \\
Occupancy & 0.52 & 0.04 & 0.01 & 6957 & 76.4 \\
Turning frequency & 0.53 & 0.06 & 0.01 & 6957 & 17.4 \\
\hline
\end{tabular}

\section{Turning frequency GAMM}

While less powerful than the occupancy GAMM, the turning model still accounted for a considerable portion of the variation in turning frequency of both smaller and larger sharks $(17 \%$; Table 1). Overall for smaller sharks, movements were more tortuous over shallower water with low chlorophyll- $a$ concentrations, while the effects of SST and SST-slope were insignificant (Table 2 and Figure 3).

Bathymetry and chlorophyll- $a$ concentration were the most influential factors for the large sharks, with higher turning frequency occurring in shallower waters and in chlorophyll- $a$ concentrations over $1 \mathrm{mg} \mathrm{m}^{-3}$ (Table 2 and Figure 3). High turning was also associated with water temperatures cooler than $22^{\circ} \mathrm{C}$, but the effect of SST slope was insignificant (Table 2 and Figure 3). Shark ID also proved significant in the turning frequency GAMM, illustrating intraspecific variation in where individuals performed higher turning frequency.

\section{Use of shark sanctuaries and estimation of fisheries interactions}

Grid occupancy analysis revealed that the shark sanctuaries of Bahamas, BVI and Saba covered 12\% $\pm 15(S D)$ of tiger shark movements. Inclusion of the Bermuda EEZ as a potential shark sanctuary substantially increased overall coverage of shark occupancy to $52 \% \pm 31(S D)$ (Wilcoxon rank-sum test; $n=24$, $Z=4.28, p<0.001)$.

Plotting EEZ overlap of all tracked sharks by month revealed that occupancy of existing sanctuaries differed considerably between large and small sharks (Figure 4). For large sharks, overall coverage provided by existing sanctuaries was low $(20 \% \pm 20 S D)$, with the highest coverage occurring during winter (peaking 50-60\%), and very little coverage during summer and autumn months. For small sharks, existing sanctuaries provided no coverage of shark movements. The addition of 
Table 2. GAMM coefficient estimates for both small and large tiger sharks.

\begin{tabular}{|c|c|c|c|c|c|c|c|c|c|c|}
\hline \multirow[b]{2}{*}{ Model } & \multicolumn{5}{|c|}{ Small } & \multicolumn{5}{|c|}{ Large } \\
\hline & Variable & edf & Ref.df & $F$ & $p$ value & Variable & edf & Ref.df & $\boldsymbol{F}$ & $p$ value \\
\hline \multirow[t]{5}{*}{ Presence/absence } & SST & 2.16 & 2.16 & 6.27 & $<0.01$ & SST & 3.26 & 3.26 & 229.75 & $<0.001$ \\
\hline & Chla_log 10 & 3.83 & 3.83 & 23.55 & $<0.001$ & Chla_log 10 & 3.97 & 3.97 & 61.57 & $<0.001$ \\
\hline & Slope_log 10 & 2.83 & 2.83 & 9.03 & $<0.001$ & Slope_log 10 & 3.76 & 3.76 & 23.14 & $<0.001$ \\
\hline & Bathymetry & 1.00 & 1.00 & 27.58 & $<0.001$ & Bathymetry & 3.94 & 3.94 & 71.35 & $<0.001$ \\
\hline & ID & 20.12 & 22.00 & 15.75 & $<0.001$ & ID & 20.12 & 22.00 & 15.75 & $<0.001$ \\
\hline \multirow[t]{5}{*}{ Occupancy } & SST & 3.80 & 3.80 & 9.09 & $<0.001$ & SST & 3.03 & 3.03 & 14.16 & $<0.001$ \\
\hline & Chla_log 10 & 2.36 & 2.36 & 5.87 & 0.018 & Chla_log 10 & 3.42 & 3.42 & 21.94 & $<0.001$ \\
\hline & Slope_log 10 & 2.55 & 2.55 & 6.36 & $<0.001$ & Slope_log 10 & 1.81 & 1.81 & 6.31 & 0.018 \\
\hline & Bathymetry & 3.89 & 3.89 & 194.11 & $<0.001$ & Bathymetry & 3.93 & 3.93 & 654.66 & $<0.001$ \\
\hline & ID & 19.84 & 22.00 & 83.10 & $<0.001$ & ID & 19.84 & 22.00 & 83.10 & $<0.001$ \\
\hline \multirow[t]{5}{*}{ Turning frequency } & SST & 2.07 & 2.07 & 1.69 & 0.2647 & SST & 3.76 & 3.76 & 25.46 & $<0.001$ \\
\hline & Chla_log 10 & 2.97 & 2.97 & 5.42 & $<0.01$ & Chla_log 10 & 3.77 & 3.77 & 36.34 & $<0.001$ \\
\hline & Slope_log 10 & 1.00 & 1.00 & 1.35 & 0.246 & Slope_log 10 & 1.00 & 1.00 & 0.32 & 0.574 \\
\hline & Bathymetry & 2.61 & 2.61 & 22.41 & $<0.001$ & Bathymetry & 3.46 & 3.46 & 82.06 & $<0.001$ \\
\hline & ID & 17.46 & 22.00 & 10.49 & $<0.001$ & ID & 17.46 & 22.00 & 10.49 & $<0.001$ \\
\hline
\end{tabular}

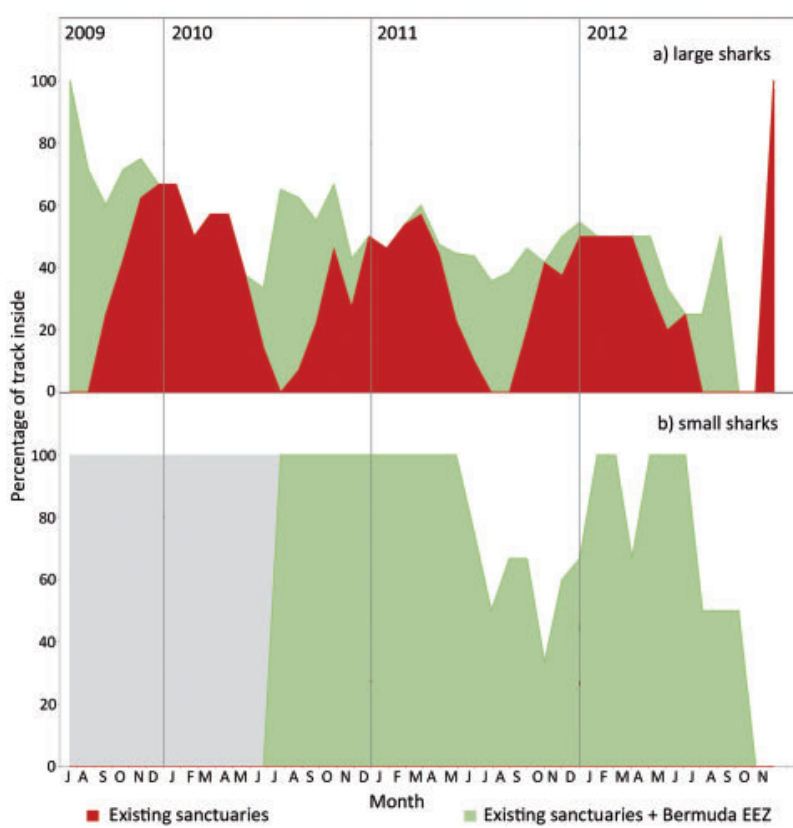

Figure 4. Monthly overlap between large (a) and small (b) tiger shark occupancy and existing shark sanctuaries (Bahamas, BVI, Saba) and with Bermuda's EEZ included. Please note no small sharks were tracked prior to June 2010.

Bermuda's EEZ as a potential shark sanctuary would provide better coverage year-round for both size classes, with overall coverage across all individuals exceeding $52 \% \pm 31$ SD. This is largely attributable to small sharks, which displayed very high overlap with Bermuda's EEZ $(81 \% \pm 27 S D)$, while the inclusion of Bermuda increased total coverage of large shark occupancy to $47 \% \pm 25 S D$.

Mapping of longline fishing effort in relation to tiger shark occupancy revealed that the highest risk of fishery interaction occurred offshore in open ocean habitat (Figure 5). Of all potential interactions, $8 \%$ occurred within existing shark sanctuaries, with $6 \%$ occurring within Bermuda's EEZ, and $86 \%$ outside of either.

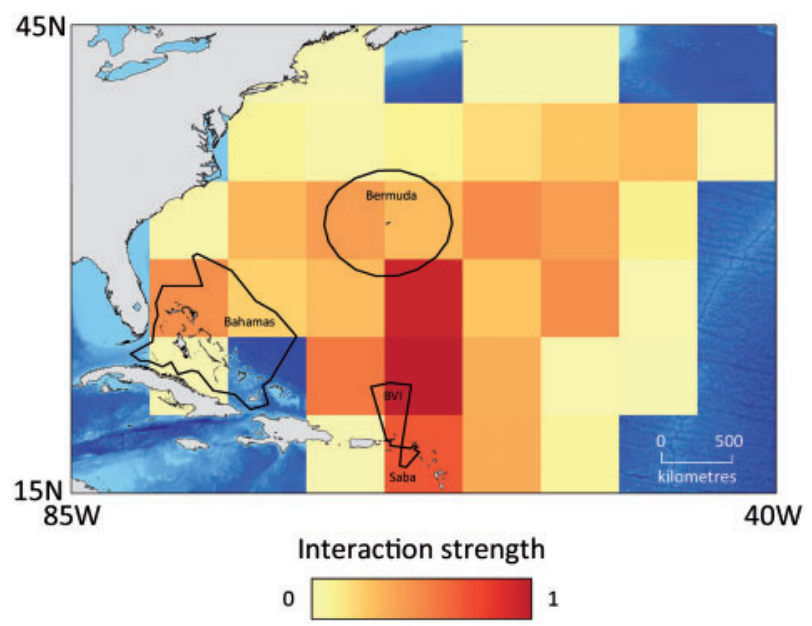

Figure 5. Map displaying the strength of interaction risk between tiger sharks and tuna longliners during 2009-2012 at a $5^{\circ} \times 5^{\circ}$ resolution. Interaction strength reveals where high tiger shark occupancy overlapped with high fishing effort. The black borders denote the EEZs of the Bahamas, British Virgin Islands, Saba, and Bermuda. Map created in ArcGIS, using GSHHG coastline data, ETOPO2v2 bathymetry data and ICCAT data on tuna longline fishing effort for the study period (hooks set per $5^{\circ} \times 5^{\circ}$ cell, 20092012).

\section{Discussion}

Our study supports the hypothesis that the spatial ecology of migratory marine predators is influenced by a combination of interacting intrinsic and extrinsic factors. In particular, we have demonstrated a marked contrast in how tiger sharks of different sizes interact with their environment, which may in part explain the patterns of partial migration observed for this species in the northwest Atlantic (Lea et al., 2015). Differences in body size between migrants and residents within a population have been reported for other evolutionary groups (Chapman et al., 2011), but rarely in elasmobranchs (Bansemer and Bennett, 2011; Lea et al., 2015). In other taxa, larger individuals may remain resident, presumed to have greater physiological tolerance for 
environmental variation, while smaller individuals migrate to track favourable conditions ("body-size" hypothesis) (Chapman et al., 2011). Notably, the opposite ontogenetic migratory pattern was seen in the tiger sharks we tracked, with potential causes discussed below. The only two small sharks $(\sim 260 \mathrm{~cm}$ total length when tagged) that performed any kind of seasonal movement away from Bermuda (as seen in Figure 2) did not do so until the second winter of their tracks, having previously overwintered at Bermuda (Lea et al., 2015). Around the time of their broader movements these two sharks were estimated to have been $\sim 280 \mathrm{~cm}$ TL, based on published growth parameters for the region (Branstetter et al., 1987), suggesting they may have been observed over the cusp of the ontogenetic shift in migratory behaviour.

\section{Environmental influence on movement behaviour}

While all the sharks associated more frequently with shallower topographical features, such as insular reefs, small, resident sharks were typically found in cooler, low chlorophyll- $a$ regions, whereas distribution of large, migratory sharks was more strongly predicted by warmer temperatures and higher chlorophyll- $a$ concentrations. The SST slope (the approximation of thermal fronts) had little influence on the presence of small tiger sharks, whereas larger sharks were present more frequently in moderate SST slopes.

As the modelling of tiger shark presence/absence only accounted for a small proportion of the observed variation in shark distribution and the random effect of shark ID was highly significant, other factors may have greater influence on tiger shark distribution, such as individual philopatry to summer foraging targets and overwintering sites (Lea et al., 2015). Combined with only a portion of the population being sampled, this individual variation may have reduced the predictive power of the presence/ absence model. Additionally, the seasonal switching of habitats between reef ecosystems and pelagic environments (Lea et al., 2015) may explain the bimodal response of large tiger shark distribution to chlorophyll. Coral reef ecosystems, where the large sharks overwinter, are highly productive environments despite low phytoplankton (and thereby low chlorophyll-a) (Tada et al., 2003), whereas offshore in pelagic habitats during summer prey availability may be strongly determined by areas of high primary productivity (Polovina et al., 2001).

In contrast the high performance of the occupancy and turning frequency models shows that an individual's own movement patterns are quite predictable based on environmental variation, and the differences between small and large sharks are still evident. Small sharks displayed higher occupancy at a range of temperatures that reflect seasonal SST changes around Bermuda, and showed more restricted space use in temperatures lower than $21^{\circ} \mathrm{C}$. In western Australia, tiger sharks are reported to leave Shark Bay when temperatures drop below $19^{\circ} \mathrm{C}$ (Wirsing et al., 2006), suggesting Bermuda waters remain warm enough to be tolerated by the smaller sharks all year as SST rarely dropped below $20^{\circ} \mathrm{C}$. Meanwhile, the large sharks in the present study adopted a warm, narrow thermal niche of $\sim 23-27^{\circ} \mathrm{C}$ (at least while at the surface), but also displayed higher turning frequency at the cooler end of this range, possibly linked to foraging in upwellings of cool, nutrient rich water. This is consistent with modelling of environmental influence on large tiger shark space use in Hawaii, which found higher occupancy in water temperatures of $23-26^{\circ} \mathrm{C}$ (Papastamatiou et al., 2013).

Following seasonal changes in oceanic temperature profiles may be an adaptation to help cue migration to coincide with temporally discrete prey availability (Møller et al., 2008), and could also represent behavioural thermoregulation to facilitate management of energetic budgets (Buckley et al., 2012). In terrestrial ectotherms, reduced energetic requirements compared to endotherms means that temperature variation, more than productivity levels, dictates animal distribution (Buckley et al., 2012), which appears to be reflected in the tracked tiger sharks: SST was considerably more important than chlorophyll in the presence/ absence model for larger sharks. But chlorophyll was more important in the occupancy and turning frequency models, suggesting that within that thermal niche productivity may better predict where the sharks spend more time.

It is reasonable to hypothesise that the contrast of residency and migration between small and large sharks may in part be due to the physiological constraints of smaller body size. Due to a higher surface area to volume ratio, smaller body size is associated with a higher relative metabolic rate per unit mass, along with higher relative drag, lower momentum and reduced thermal inertia (Weihs, 1977; Peters, 1986). In addition, large sharks achieve greater lift due to allometric scaling of morphology, and they possess comparatively larger, more buoyant livers than smaller conspecifics (Iosilevskii and Papastamatiou, 2016). A comparatively larger liver may also facilitate migration through provision of increased energy reserves (Del Raye et al., 2013). Combined this means that the relative energetic cost of transport decreases with increasing body size, particularly in warmer water, such that for the same metabolic rate larger sharks may be able to travel farther and faster than smaller sharks (Iosilevskii and Papastamatiou, 2016).

The large tiger sharks also spent more time and performed more tortuous movements in areas of higher chlorophyll, indicative of a greater ability to target areas of high biomass with productive foraging opportunities (Hays et al., 2006). It may be that large shark environmental preferences and migrations serve to increase encounter rates with prey species, such as loggerhead turtles Caretta caretta, which have been reported to overlap seasonally with tiger shark movements in the northwest Atlantic (Lea et al., 2015). Long-distance migrations require an ability to navigate or orientate effectively, potentially guided by factors other than those recorded here, e.g. memory, olfaction gradients, magnetic fields (Papastamatiou et al., 2011). Indeed, the ontogeny of migration targets for turtle species appears to be informed by individual experience, with adults migrating to regions they encountered as drifting hatchlings (Scott et al., 2014). Larger (i.e. older) tiger sharks may increase their encounter rates with more productive areas based on previous experience, which may explain their increased association with higher chlorophyll- $a$ concentrations compared to smaller sharks.

Our finding that the large tiger sharks were present more frequently in areas of steeper thermal gradients supports recent work on tiger sharks tagged in the Bahamas and USA (Queiroz et al., 2016) and is consistent with this being a more general behavioural pattern among marine predators searching for prey in the pelagic environment (Block et al., 2011; Queiroz et al., 2012). The strong association with shallower water for both large and small sharks reflects seasonally high occupancy around Caribbean islands and Bermuda, and may also imply an affinity 
for seamounts whilst offshore, which could be areas of high productivity due to associated upwellings (Oschlies and Garçon, 1998).

\section{Management implications of partial migration}

Partial migration patterns associated with ontogeny have important implications for precautionary management aimed at reducing fisheries interactions and ensuring population integrity. Given the demonstrated relationship of high tiger shark occupancy around islands and seamounts, reasonable coverage of their movements could be achieved with spatial management options such as MPAs that prohibit shark fishing around these locations. Certain island nations have already designated "shark sanctuaries" specifically for this purpose (e.g. Bahamas, British Virgin Islands), but the tracked sharks only spent $12 \%$ of their time within these areas. This is less time than previously reported for tiger sharks tracked from the Bahamas and USA [ 30\% (Graham et al., 2016)]. However, the latter individuals were predominantly female, which could be more resident than the migratory males tracked in our study (Hammerschlag et al., 2012), and they were tracked largely during winter and spring (Graham et al., 2016), when migrants also spent more time in the existing MPAs (see Figure 4). But spatial coverage of tiger shark movements could be increased to $52 \%$ if Bermuda were designated an MPA for sharks, as maturing sub-adults display such high residency in the area (Lea et al., 2015), which could be valuable for regional population stability (Prince, 2005).

However, even with Bermuda included as a potential MPA, $86 \%$ of all potential longline fisheries interaction risk occurred outside of the expanded MPAs. This suggests that, due to the broad geographical scale of intensive fishing pressure in the northern Atlantic (Queiroz et al., 2016), static spatial management options such as MPAs may have limited power to reduce fishing mortality for highly migratory species such as the tiger shark. Although tiger sharks are managed in US Atlantic and Gulf of Mexico fisheries through a total allowable catch (NOAA, 2016), where over $80 \%$ of individuals are released alive (Dapp et al., 2017), they also make extensive use of open ocean in the Atlantic (Hammerschlag et al., 2012; Lea et al., 2015; Afonso et al., 2017), which is fished by a variety of international fleets. Consequently, management strategies targeting the population as a whole may need to adopt an array of approaches, including modification of fishing practices, which will require significant international cooperation. Considering the seemingly low boatside mortality of tiger sharks in the US longline fishery (Dapp et al., 2017), precautionary imposition of release practices and quotas specific to tiger sharks across the Atlantic could be considered, as has been proposed for blue sharks Prionace glauca in the northeast Atlantic (Queiroz et al., 2012).

Given the significant association found between tiger shark movements and environmental features, future management and conservation efforts should also consider how tiger shark distributions and migration patterns may shift with the changing climate. As sea temperatures rise and the severity of climate events such as El Niño increase (Cobb et al., 2003; Meehl et al., 2007), shifts in shark distribution may occur that will require dynamic modification of management strategies. For instance, modelling of 23 different marine predators in the Pacific under increasing SST and changing chlorophyll- $a$ distributions predicted a change of up to $35 \%$ in core habitat, which may increase migration times, exacerbate declines and inhibit recovery (Hazen et al., 2013). If applicable to tiger sharks in the Atlantic, foraging patches along productive isotherms may be pushed further north under increasing SST landscapes, forcing migrations away from southern overwintering sites to be longer and potentially exacerbating the metabolic costs of migration and putting sharks at greater risk of pelagic fisheries interactions, thereby reducing population viability. Similarly, such SST shifts could also modify physiological costs of winter residency patterns of juvenile sharks, further complicating population impacts.

\section{Conclusions}

This study demonstrated how the influence of environmental factors (e.g. temperature and productivity) on the spatial ecology of highly migratory marine predators can be dependent on intrinsic state (e.g. body size). We revealed a marked contrast in tiger shark responses to environmental variation based on individual size. Larger sharks occupied a warmer, narrower thermal niche that may represent behavioural thermoregulation or use of environmental cues to possibly time migration with temporally discrete prey availability. The large sharks also more frequently occupied areas of increased productivity, consistent with an ontogenetic shift in foraging strategy and diet. It appears reasonable to suggest that the partial migrations of tiger sharks in the northwest Atlantic represent a conditional strategy whereby responses to an individual's environment are governed by their intrinsic state, driving an ontogenetic shift in response to environmental variation and migration propensity.

Partial migration associated with ontogeny carries with it significant implications for managing fisheries interactions, such that all subunits of a population remain functional to ensure ongoing recruitment. It was revealed that the designation of Bermuda's EEZ as a shark sanctuary would increase coverage of tiger shark movements in the northwest Atlantic significantly, providing high coverage for still maturing individuals. However, most of potential interactions between tiger sharks and longline fishing vessels still occurred outside of these areas on the high seas, highlighting the need for modifications of fishing practices to ensure effective management of the population as a whole.

\section{Supplementary material}

Supplementary material is available at the ICESJMS online version of the manuscript.

\section{Acknowledgements}

Funding for this study was provided by the Guy Harvey Ocean Foundation, Guy Harvey Research Institute, the Shark Foundation (Hai Stiftung), and the Bermuda Shark Project. Funding for data analysis was provided by the UK Natural Environment Research Council (NERC) “Oceans 2025” Strategic Research Programme in which D.W.S. is a principal investigator, a Fundação para a Ciência e a Tecnologia (FCT) grant (PTDC/ MAR/100345/2008) to N.Q. and D.W.S., and an FCT grant (SFRH/BD/68717/2010) to L.L.S., an FCT Investigator Fellowship to N.Q. (IF/01611/2013). J.S.E.L. was supported by Danah Divers and the Marine Biological Association of the UK (MBA) and D.W.S. by an MBA Senior Research Fellowship. This manuscript is dedicated to Dr. Neil Burnie who founded the Bermuda Shark Project-his drive and enthusiasm made the present work possible. 


\section{References}

Afonso, A. S., Garla, R., Hazin, F. H. V., and Klimley, A. P. 2017. Tiger sharks can connect equatorial habitats and fisheries across the Atlantic Ocean basin. PLoS One, 12: e0184763.

Bansemer, C. S., and Bennett, M. B. 2011. Sex- and maturity-based differences in movement and migration patterns of grey nurse shark, Carcharias taurus, along the eastern coast of Australia. Marine and Freshwater Research, 62: 596-606.

Baum, J. K., and Myers, R. A. 2004. Shifting baselines and the decline of pelagic sharks in the Gulf of Mexico. Ecology Letters, 7: 135-145.

Baum, J. K., and Blanchard, W. 2010. Inferring shark population trends from generalized linear mixed models of pelagic longline catch and effort data. Fisheries Research, 102: 229-239.

Block, B. A., Jonsen, I. D., Jorgensen, S. J., Winship, A. J., Shaffer, S. A., Bograd, S. J., Hazen, E. L., Foley, D. G., Breed, G. A., Harrison, A.-L., et al. 2011. Tracking apex marine predator movements in a dynamic ocean. Nature, 475: 86-90.

Branstetter, S., Musick, J., and Colvocoresses, J. 1987. A comparison of the age and growth of the tiger shark, Galeocerdo cuvier, from off Virginia and from the northern Gulf of Mexico. Fishery Bulletin, 85: 269-279.

Buckley, L. B., Hurlbert, A. H., and Jetz, W. 2012. Broad-scale ecological implications of ectothermy and endothermy in changing environments. Global Ecology and Biogeography, 21: 873-885.

Carlson, J. K., Hale, L. F., Morgan, A., and Burgess, G. 2012. Relative abundance and size of coastal sharks derived from commercial shark longline catch and effort data. Journal of Fish Biology, 80: 1749-1764.

Chapman, B. B., Brönmark, C., Nilsson, J.-Å., and Hansson, L.-A. 2011. The ecology and evolution of partial migration. Oikos, 120: $1764-1775$.

Chapman, B. B., Hulthén, K., Brodersen, J., Nilsson, P. A., Skov, C., Hansson, L.-A., and Brönmark, C. 2012. Partial migration in fishes: causes and consequences. Journal of Fish Biology, 81: 456-478.

Cobb, K. M., Charles, C. D., Cheng, H., and Edwards, R. L. 2003. El Nino/Southern Oscillation and tropical Pacific climate during the last millennium. Nature, 424: 271-276.

Dapp, D., Huveneers, C., Walker, T., Mandelman, J., Kerstetter, D., and Reina, R. 2017. Using logbook data to determine the immediate mortality of blue sharks. Fishery Bulletin, 115: 27-41.

Del Raye, G., Jorgensen, S. J., Krumhansl, K., Ezcurra, J. M., and Block, B. A. 2013. Travelling light: white sharks (Carcharodon carcharias) rely on body lipid stores to power ocean-basin scale migration. Proceedings of the Royal Society B: Biological Sciences, 280: 20130836.

Domeier, M. L., and Nasby-Lucas, N. 2013. Two-year migration of adult female white sharks (Carcharodon carcharias) reveals widely separated nursery areas and conservation concerns. Animal Biotelemetry, 1: 1-10.

Domingo, A., Coelho, R., Cortes, E., Garcia-Cortes, B., Mas, F., Mejuto, J., Miller, P., Ramos-Cartelle, A., Santos, M. N., and Yokawa, K. 2016. Is the tiger shark Galeocerdo cuvier a coastal species?: Expanding its distribution range in the Atlantic Ocean using at-sea observer data. Journal of Fish Biology, 88: 1223-1228.

Dulvy, N. K., Fowler, S. L., Musick, J. A., Cavanagh, R. D., Kyne, P. M., Harrison, L. R., Carlson, J. K., Davidson, L. N. K., Fordham, S. V., Francis, M. P., et al. 2014. Extinction risk and conservation of the world's sharks and rays. eLife, 3 .

Ferretti, F., Myers, R. A., Serena, F., and Lotze, H. K. 2008. Loss of large predatory sharks from the Mediterranean Sea. Conservation Biology, 22: 952-964.

González-Solís, J., Croxall, J. P., Oro, D., and Ruiz, X. 2007. Trans-equatorial migration and mixing in the wintering areas of a pelagic seabird. Frontiers in Ecology and the Environment, 5: 297-301.
Graham, F., Rynne, P., Estevanez, M., Luo, J., Ault, J. S., Hammerschlag, N., and Schoeman, D. 2016. Use of marine protected areas and exclusive economic zones in the subtropical western North Atlantic Ocean by large highly mobile sharks. Diversity and Distributions, 22: 534-546.

Hammerschlag, N., Gallagher, A. J., Wester, J., Luo, J., and Ault, J. S. 2012. Don't bite the hand that feeds: assessing ecological impacts of provisioning ecotourism on an apex marine predator. Functional Ecology, 26: 567-576.

Hays, G. C., Ferreira, L. C., Sequeira, A. M. M., Meekan, M. G., Duarte, C. M., Bailey, H., Bailleul, F., Bowen, W. D., Caley, M. J., Costa, D. P., et al. 2016. Key questions in marine megafauna movement ecology. Trends in Ecology and Evolution, 31: 463-475.

Hays, G. C., Åkesson, S., Godley, B. J., Luschi, P., and Santidrian, P. 2001. The implications of location accuracy for the interpretation of satellite-tracking data. Animal Behaviour, 61: 1035-1040.

Hays, G. C., Hobson, V. J., Metcalfe, J. D., Righton, D., and Sims, D. W. 2006. Flexible foraging movements of leatherback turtles across the North Atlantic Ocean. Ecology, 87: 2647-2656.

Hazel, J. 2009. Evaluation of fast-acquisition GPS in stationary tests and fine-scale tracking of green turtles. Journal of Experimental Marine Biology and Ecology, 374: 58-68.

Hazen, E. L., Jorgensen, S., Rykaczewski, R. R., Bograd, S. J., Foley, D. G., Jonsen, I. D., Shaffer, S. A., et al. 2013. Predicted habitat shifts of Pacific top predators in a changing climate. Nature Climate Change, 3: 234-238.

Iosilevskii, G., and Papastamatiou, Y. P. 2016. Relations between morphology, buoyancy and energetics of requiem sharks. Royal Society Open Science, 3: 160406.

Lea, J. S. E., Wetherbee, B. M., Queiroz, N., Burnie, N., Aming, C., Sousa, L. L., Mucientes, G. R., et al. 2015. Repeated, long-distance migrations by a philopatric predator targeting highly contrasting ecosystems. Scientific Reports, 5: 11202.

Mansfield, K. L., Wyneken, J., Porter, W. P., and Luo, J. 2014. First satellite tracks of neonate sea turtles redefine the 'lost years' oceanic niche. Proceedings of the Royal Society B: Biological Sciences, 281: 20133039.

McMahon, C. R., and Hays, G. C. 2006. Thermal niche, large-scale movements and implications of climate change for a critically endangered marine vertebrate. Global Change Biology, 12: $1330-1338$.

Meehl, G. A., Stocker, T. F., Collins, W. D., Friedlingstein, P., Gaye, A. T., Gregory, J. M., Kitoh, A., et al. 2007. Global climate projections. Climate Change, 3495: 747-845.

Møller, A. P., Rubolini, D., and Lehikoinen, E. 2008. Populations of migratory bird species that did not show a phenological response to climate change are declining. Proceedings of the National Academy of Sciences USA, 105: 16195-16200.

NOAA. 2016. NOAA Fisheries a Final Rule Regarding the 2016 Atlantic Shark Commercial Fishing Season: Office of Sustainable Fisheries. Office of Sustainable Fisheries. http://www.nmfs.noaa. gov/sfa/hms/news/news_list/2015/11/113015_2016_shk_seasons. htm (last accessed 7 Febraury 2017).

Oschlies, A., and Garçon, V. 1998. Eddy-induced enhancement of primary production in a model of the North Atlantic Ocean. Nature, 394: 266-269.

Papastamatiou, Y. P., Cartamil, D. P., Lowe, C. G., Meyer, C. G., Wetherbee, B. M., and Holland, K. N. 2011. Scales of orientation, directed walks and movement path structure in sharks. Journal of Animal Ecology, 80: 864-874.

Papastamatiou, Y. P., Meyer, C. G., Carvalho, F., Dale, J. J., Hutchinson, M. R., and Holland, K. N. 2013. Telemetry and random-walk models reveal complex patterns of partial migration in a large marine predator. Ecology, 94: 2595-2606.

Papastamatiou, Y. P., Watanabe, Y. Y., Bradley, D., Dee, L. E., Weng, K., Lowe, C. G., and Caselle, J. E. 2015. Drivers of daily routines 
in an ectothermic marine predator: hunt warm, rest warmer?. PLoS One, 10: e0127807.

Pauly, D., Christensen, V., Dalsgaard, J., Froese, R., and Torres, F. 1998. Fishing down marine food webs. Science, 279: 860-863.

Peters, R. H. 1986. The Ecological Implications of Body Size. Cambridge University Press, Cambridge, UK.

Polovina, J. J., Howell, E., Kobayashi, D. R., and Seki, M. P. 2001. The transition zone chlorophyll front, a dynamic global feature defining migration and forage habitat for marine resources. Progress in Oceanography, 49: 469-483.

Prince, J. D. 2005. Gauntlet fisheries for elasmobranchs-the secret of sustainable shark fisheries. Journal of Northwest Atlantic Fishery Science, 35: 407-416.

Queiroz, N., Humphries, N. E., Noble, L. R., Santos, A. M., Sims, D. W., and Ropert-Coudert, Y. 2012. Spatial dynamics and expanded vertical niche of blue sharks in oceanographic fronts reveal habitat targets for conservation. PLoS One, 7: e32374.

Queiroz, N., Humphries, N. E., Mucientes, G., Hammerschlag, N., Lima, F. P., Scales, K. L., Miller, P. I., Sousa, L. L., Seabra, R., and Sims, D. W. 2016. Ocean-wide tracking of pelagic sharks reveals extent of overlap with longline fishing hotspots. Proceedings of the National Academy of Sciences USA, 113: 1582-1587.

Scales, K. L., Miller, P. I., Hawkes, L. A., Ingram, S. N., Sims, D. W., Votier, S. C., and Punt, A. 2014. Review: on the front line: frontal zones as priority at-sea conservation areas for mobile marine vertebrates. Journal of Applied Ecology, 51: 1575-1583.

Scott, R., Marsh, R., and Hays, G. C. 2014. Ontogeny of long distance migration. Ecology, 95: 2840-2850.

Simpfendorfer, C. 2009. Galeocerdo cuvier. The IUCN Red List of Threatened Species. http://www.iucnredlist.org (last accessed 7 February 2017).

Sousa, L. L., Queiroz, N., Mucientes, G., Humphries, N. E., and Sims, D. W. 2016. Environmental influence on the seasonal movements of satellite-tracked ocean sunfish Mola mola in the north-east Atlantic. Animal Biotelemetry, 4: 7.

Tada, K., Sakai, K., Nakano, Y., Takemura, A., and Montani, S. 2003. Size-fractionated phytoplankton biomass in coral reef waters off Sesoko Island, Okinawa, Japan. Journal of Plankton Research, 25: 991-997.

Wearmouth, V. J., and Sims, D. W. 2008. Sexual segregation in marine fish, reptiles, birds and mammals behaviour patterns, mechanisms and conservation implications. Advances in Marine Biology, 54: 107-170.

Weihs, D. 1977. Effects of size on sustained swimming speeds of aquatic organisms. In Scale Effects in Animal Locomotion, pp. 333-338. Ed. by T. J. Pedley. Academic Press, New York.

Weng, K. C., Foley, D. G., Ganong, J. E., Perle, C., Shillinger, G. L., and Block, B. A. 2008. Migration of an upper trophic level predator, the salmon shark Lamna ditropis, between distant ecoregions. Marine Ecology Progress Series, 372: 253-264.

Werry, J. M., Planes, S., Berumen, M. L., Lee, K. A., Braun, C. D., Clua, E., and Klimley, A. P. 2014. Reef-fidelity and migration of tiger sharks, Galeocerdo cuvier, across the Coral Sea. PLoS One, 9: e83249.

Wirsing, A. J., Heithaus, M. R., and Dill, L. M. 2006. Tiger shark (Galeocerdo cuvier) abundance and growth in a subtropical embayment: evidence from 7 years of standardized fishing effort. Marine Biology, 149: 961-968.

Worm, B., Davis, B., Kettemer, L., Ward-Paige, C. A., Chapman, D. Heithaus, M. R., Kessel, S. T., et al. 2013. Global catches, exploitation rates, and rebuilding options for sharks. Marine Policy, 40: 194-204.

Zuur, A., Ieno, F., Walker, N., Saveliev, A., and Simth, G. 2009. Mixed Effects Models and Extensions in Ecology with R. Springer, New York. 